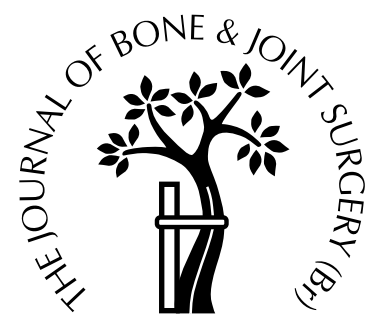

\title{
Wound healing after implant surgery in HIV-positive patients
}

\author{
W. J. Harrison, C. P. Lewis, C. B. D. Lavy \\ From the College of Medicine and Queen Elizabeth Hospital, Blantyre, Malawi
}

W e performed a prospective, blind, controlled study on wound infection after implant surgery involving 41 procedures in patients infected with the human immunodeficiency virus (HIV) and 141 in HIV-negative patients. The patients were staged clinically and the CD4 cell count determined. Wound infection was assessed using the asepsis wound score. A risk category was allocated to account for presurgical contamination.

In HIV-positive patients, with no preoperative contamination, the incidence of wound infection (3.5\%) was comparable with that of the HIV-negative group (5\%; $p=0.396)$. The $\mathrm{CD} 4$ cell count did not affect the incidence of infection $(r=0.16)$. When there was preoperative contamination, the incidence of infection in HIV-positive patients increased markedly $(42 \%)$ compared with that in HIV-negative patients $(11 \% ; p=0.084)$.

Our results show that when no contamination has occurred implant surgery may be undertaken safely in HIV-positive patients.

J Bone Joint Surg [Br] 2002;84-B:802-6.

Received 6 July 2001; Accepted after revision 16 November 2001

Infection is a serious complication of operations which involve implants in both trauma and elective surgery. Certain patients, such as those taking immunosuppressive drugs, have an increased risk of infection. In such patients the risk of wound sepsis must be weighed carefully against the potential benefits of surgery, and the use of implants in particular.

Patients who are infected with the human immunodeficiency virus (HIV) suffer progressive deterioration in immunity as indicated by a fall in the T-helper (CD4) cell

W. J. Harrison, FRCS (Trauma \& Orth), Specialist Registrar

C. P. Lewis, MRCS, Senior House Officer

C. B. D. Lavy, FRCS, Associate Professor

The Queen Elizabeth Hospital, Blantyre, Malawi.

Correspondence should be sent to Mr W. J. Harrison at PO Box 31236 , Chichiri, Blantyre 3, Malawi.

C2002 British Editorial Society of Bone and Joint Surgery 0301-620X/02/612641\$2.00 count. Studies suggest that in such patients the risk of wound infection increases as the immune status deteriorates. $^{1-4}$

We therefore undertook a prospective, blind, controlled study to quantify the incidence of wound infection after implant surgery in HIV-positive patients and to assess the role of the CD4 cell count as a marker of an increased risk of developing an infection.

\section{Patients and Methods}

All adult patients undergoing implant surgery were counselled for HIV testing and those who consented to testing were entered into the study.

HIV testing. Two blood samples were taken immediately before the induction of anaesthesia. On the first sample HIV testing was undertaken using the HIV spot test (Genelabs Diagnostics Pte Ltd, Singapore). In those patients with a positive result, a CD4 cell count was undertaken on the second sample. All patients were clinically staged for HIV disease according to the WHO criteria. ${ }^{5}$ This assessment was made by a neutral observer, blind to the HIV status, and was not seen by the operating surgeon.

Wound scoring. Assessment of healing and infective complications was made using the asepsis wound scoring system $^{6}$ (Table I) as recommended by the Surgical Infection Study Group. ${ }^{7}$ This describes the appearance of the wound and the necessity for further treatment, such as the administration of antibiotics. The maximum score is 70 . It is very sensitive and allows objective appraisal of infection, and its severity. For the purpose of our study, a score of 0 to 10 was considered to represent normal wound healing, and a score of more than 10 an infection. This confers a sensitive, if arbitrary, definition of infection.

A single neutral observer (CPL) recorded the scores at 5 days, 2 and 6 weeks, and at 3 months after operation. The highest score for each patient was adopted. Both the operating surgeons and the observer were blind to the HIV status of the patient. All patients were treated as potentially HIVpositive and suitable precautions were taken.

Patients. A total of 180 patients consented to enter the study; 39 were HIV-positive and accounted for 41 (22\%) of the 185 separate surgical implantation procedures. There was therefore a control group of 141 HIV-negative patients. 
Table I. Asepsis scoring system used to assess wound healing and infective complications after implant surgery

\begin{tabular}{|c|c|c|c|c|c|c|c|}
\hline & \multicolumn{6}{|c|}{ \% wound involved } & \\
\hline & $\mathbf{0}$ & $<20$ & 20 to 39 & 40 to 59 & 60 to 79 & $\geq 80$ & \\
\hline \multicolumn{8}{|l|}{ Appearance of wound } \\
\hline Serous exudate & 0 & 1 & 2 & 3 & 4 & 5 & \\
\hline Erythema & 0 & 1 & 2 & 3 & 4 & 5 & \\
\hline Purulent exudate & 0 & 2 & 4 & 6 & 8 & 10 & \\
\hline Separation of deep tissues & 0 & 2 & 4 & 6 & 8 & 10 & \\
\hline \multicolumn{8}{|l|}{ Additional treatments } \\
\hline Antibiotics & & & & & & & 10 \\
\hline Drainage of pus (LA*) & & & & & & & 5 \\
\hline Debridement of wound (GA $\dagger$ ) & & & & & & & 10 \\
\hline Isolation of bacteria & & & & & & & 10 \\
\hline Inpatient stay $>14$ days & & & & & & & 5 \\
\hline Maximum score & & & & & & & 70 \\
\hline
\end{tabular}

* LA, local or no anaesthetic

$\dagger \mathrm{GA}$, general or regional anaesthetic

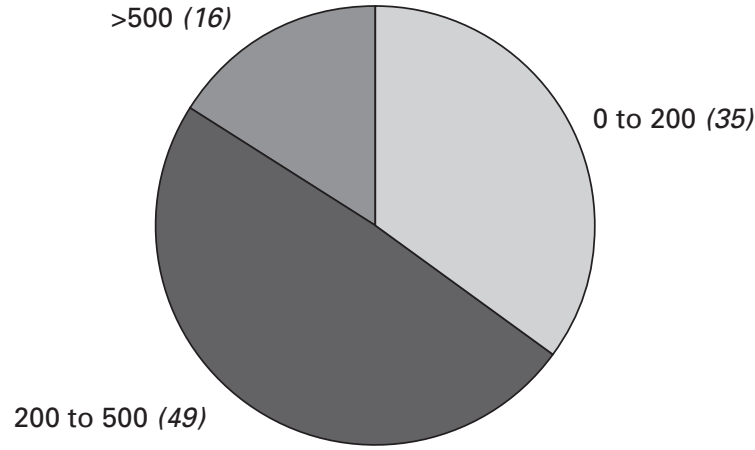

Fig. 1

Pie chart showing the distribution of the CD4 cell counts, in 37 HIV-positive patients.

As the follow-up data were incomplete for ten patients (1 HIV-positive) we analysed the data for only 170 patients who had 175 procedures. The mean age of the HIV-positive group was 37 years (21 to 54) and of the HIV-negative group 36 years (15 to 76 ). No patient had received antiretroviral drug therapy and none had diabetes, psoriasis, tuberculosis, or took steroids or other immunosuppressive medication.

WHO staging. ${ }^{5}$ The WHO clinical staging for HIV-positive patients was as follows: stage 0, $31(80 \%)$, stage 1, $3(8 \%)$, stage 2, $2(5 \%)$, stage 3, $2(5 \%)$; and not known, 1 (2\%).

CD4 cell counts. CD4 cell counts were divided into the groups recommended by the WHO staging criteria (Fig. 1) The cell counts were known for 37 of the HIV-positive patients and were less than the normal value of 1000 cells/ $\mathrm{mm}^{3}$

Type of procedure. The procedures fell into four groups: internal fixation of fresh fractures, reconstruction for nonunion, and arthrodesis or arthroplasty for joint disease (Fig. 2).

There was a higher proportion of reconstructions in the HIV-positive group, and relatively more fixations of fresh fractures in the HIV-negative group. There may be an association between HIV disease and nonunion. Closed fractures were not treated surgically until the soft tissues were in a satisfactory condition, which was sometimes up to two weeks after injury.

All patients received a standard regime of antibiotic prophylaxis with a single intravenous dose of cephazolin $(1 \mathrm{~g})$ given at induction of anaesthesia. The method of skin preparation with chlorhexidine and cetrimide solution followed by povidone iodine was standardised. A standard sterile dressing was used and wounds were not inspected until the fifth postoperative day. Surgical drains were not used. Sutures were removed two weeks after operation.

Type of implant (Fig. 3). The implant was graded in order of increasing size: wires or screws, plate and screws, intramedullary nail, and arthroplasty. Both the HIV-positive and negative groups were well matched in regard to the distribution of types of implant. This gave a good indicator of the magnitude of the surgery, the length of incisions and the duration of procedures, although these variables were not individually analysed.

Infection risk category. An infection risk category was allocated before operation to each procedure according to the state of the soft tissues as follows: 0, ideal surgical conditions as in closed fractures or elective procedures with healthy skin and 1, procedures on fresh open fractures, nonunion of previously open fractures, or previous surgery at that site. Analysis of the risk categories was separated to minimise its confounding influence. A total of 136 procedures (28 HIV-positive; 108, HIV-negative) was undertaken in risk category 0 and 39 (12 HIV-positive; $27 \mathrm{HIV}$ negative) in risk category 1 .

Statistical analysis. Analysis was carried out using the paired Student $t$-test with the level of significance being set at $\mathrm{p} \leq 0.05$.

\section{Results}

Defaulters. Of the ten patients who did not complete follow-up for six weeks, none had wound problems up to 


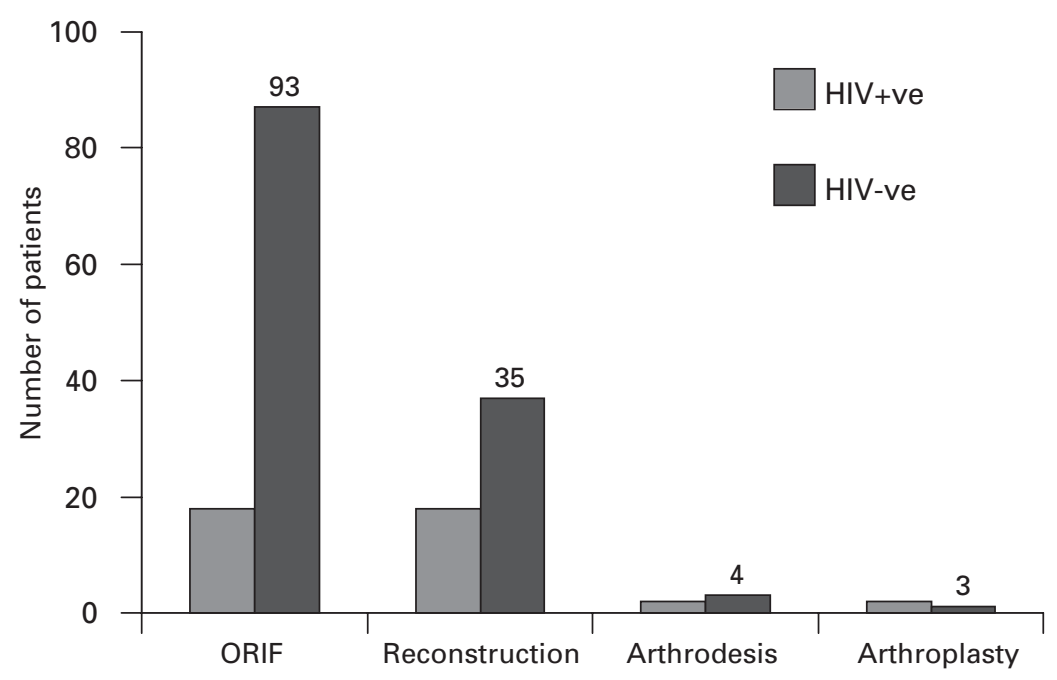

Fig. 2

Graph showing the types of procedure carried out on the 38 HIV-positive (40 procedures) and the 132 HIVnegative patients (135 procedures) (ORIF, open reduction and internal fixation).

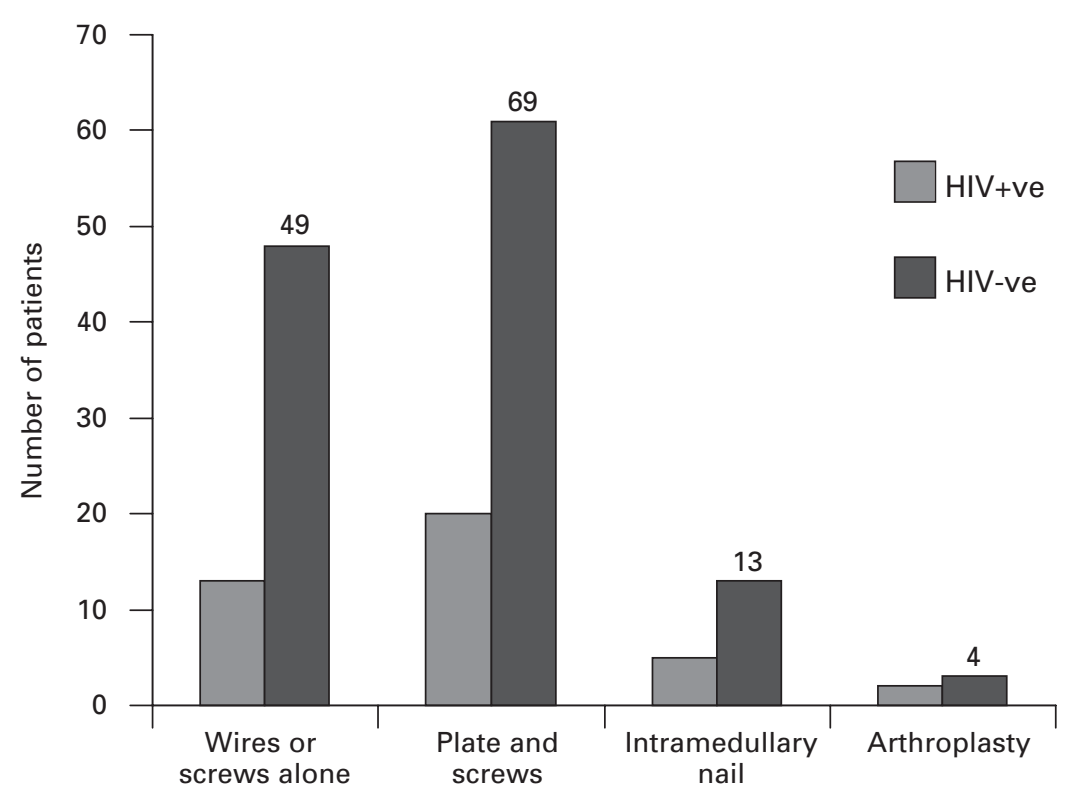

Fig. 3

Graph showing the types of implant used in the 38 HIVpositive (40 procedures) and the 132 HIV-negative patients (135 procedures).

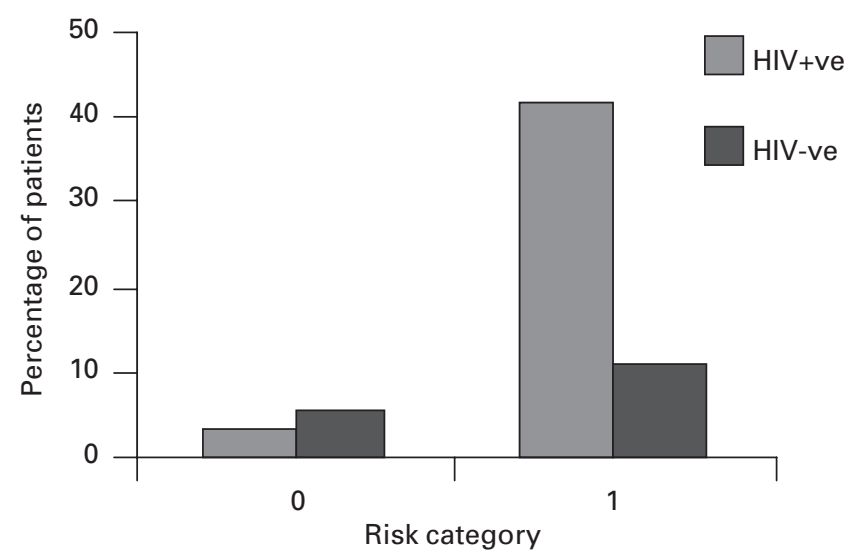

Fig. 4

Graph showing the percentage of HIV-positive and HIV-negative patients with aninfection (asepsis score $>10$ ) in each risk category afterimplant surgery. the time of discharge. In the only HIV-positive defaulter the sutures were removed from a normally healed wound (asepsis score 0) at two weeks. He failed to attend for further review.

Wound infections. The percentage of patients with asepsis scores greater than 10 (infections) in each risk category is shown in Figure 4. This definition of infection may portray a higher rate of infection than in other studies, but the listing of each infected patient in Table II qualifies this.

For the 136 procedures on patients in risk category 0 no significant difference $(p=0.396)$ was found in the incidence of infection between HIV-positive and HIV-negative patients.

There was also no significant difference $(p=0.084)$ between HIV-positive and HIV-negative patients in 39 procedures in risk category 1. A comparison of HIVpositive patients with open fractures (12) with those with 
Table II. Details and risk category of the infected HIV-positive and the HIV-negative patients after implant surgery

\begin{tabular}{|c|c|c|c|c|c|c|c|}
\hline $\begin{array}{l}\text { Case } \\
\text { number }\end{array}$ & $\begin{array}{l}\text { WHO } \\
\text { stage }\end{array}$ & $\begin{array}{l}\text { CD4 cell } \\
\text { count }\end{array}$ & $\begin{array}{l}\text { Risk } \\
\text { category }\end{array}$ & $\begin{array}{l}\text { Procedure } \\
\text { (site) }\end{array}$ & $\begin{array}{l}\text { Peak } \\
\text { asepsis } \\
\text { score }\end{array}$ & Organism & $\begin{array}{l}\text { Intervention } \\
\text { (outcome) }\end{array}$ \\
\hline \multicolumn{8}{|c|}{ HIV-positive } \\
\hline 1 & 2 & 113 & 0 & Arthrodesis (ankle) & 26 & Staph aureus & Antibiotics (resolved) \\
\hline 2 & 0 & 290 & 1 & Plate nonunion (forearm) & 12 & Unknown & Antibiotics (resolved) \\
\hline 3 & 0 & 213 & 1 & Tension band wiring (patella) & 19 & No growth & Antibiotics (resolved) \\
\hline 4 & 1 & 369 & 1 & Plate nonunion (forearm) & 13 & No growth & Antibiotics (resolved) \\
\hline 5 & 0 & 225 & 1 & Plate nonunion (forearm) & 40 & Unknown & Debridement, antibiotics (suppressed) \\
\hline 6 & 0 & 177 & 1 & Nail (femur) & 11 & Unknown & Antibiotics (resolved) \\
\hline \multicolumn{8}{|c|}{ HIV-negative } \\
\hline 7 & 2 & & 0 & Nail (femur) & 28 & Staph aureus & Antibiotics (resolved) \\
\hline 8 & 0 & & 0 & Nail (femur) & 30 & Unknown & Antibiotics (resolved) \\
\hline 9 & 0 & & 0 & Plate (forearm) & 36 & No growth & Metalware removed (cross-union) \\
\hline 10 & 0 & & 0 & Plate nonunion (tibia) & 12 & Staph aureus & Dressings (resolved) \\
\hline 11 & 0 & & 1 & Plate (forearm) & 23 & Unknown & Metalware removed (resolved) \\
\hline 12 & 0 & & 1 & Plate (ulna) & 25 & Staph aureus & Metalware removed (resolved) \\
\hline 13 & 0 & & 0 & Fusion $(\mathrm{C} 1, \mathrm{C} 2)$ & 12 & Unknown & Antibiotics (resolved) \\
\hline 14 & 0 & & 0 & ORIF (acetabulum) & 13 & No growth & Antibiotics (resolved) \\
\hline 15 & 0 & & 1 & Plate (phalanx) & 19 & No growth & Antibiotics (resolved) \\
\hline
\end{tabular}

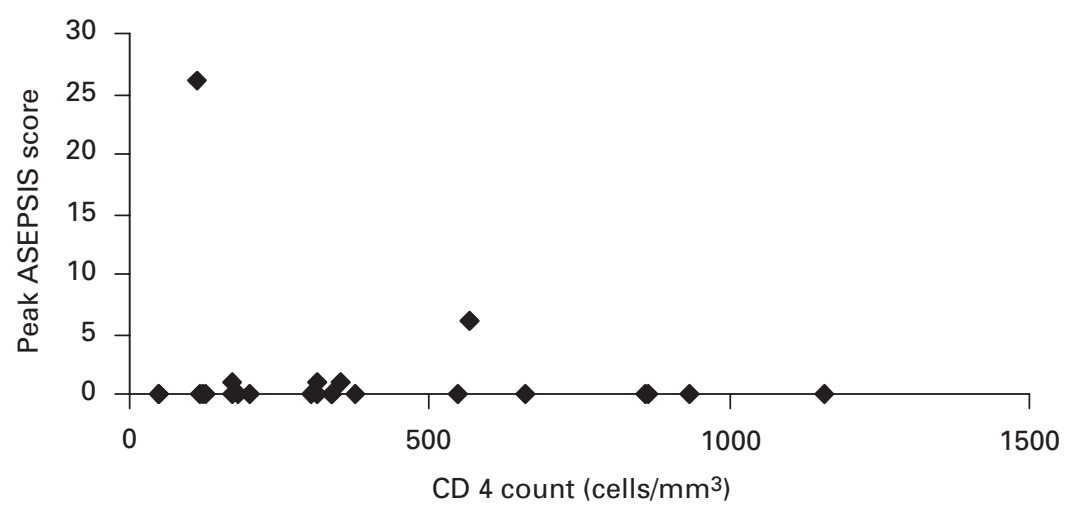

Fig. 5

Graph showing the correlation between the CD4 cell count and the peak asepsis score for the 28 HIV-positive patients in risk category 0 .

closed fractures (5) showed a significant difference in the incidence of infection ( $5 v 1 ; \mathrm{p}=0.037)$.

Within risk category 0 , of the $28 \mathrm{HIV}$-positive patients only one (case 1) had a wound infection. No correlation was shown between the asepsis score and the CD4 cell count for patients in risk category 0 (correlation coefficient $=0.16$; Fig. 5 ). In risk category 1 the numbers were too small to allow analysis of the effect of the CD4 cell count.

\section{Discussion}

The earlier studies of Hoekman et $\mathrm{al}^{1}$ and Jellis ${ }^{2}$ suggested that symptomatic HIV-positive patients had a high incidence of wound infection, $24 \%$ and $40 \%$, respectively, after implant surgery. Paiement et $\mathrm{al}^{8}$ also found an increased risk of wound infection in HIV-positive patients. Their study noted a particularly high rate of infection after internal fixation of open fractures in asymptomatic HIV-positive patients $(56 \%)$. A recent review has suggested that implant surgery should not be undertaken in regions with a high seroprevalence of HIV. ${ }^{9}$
The studies of Hoekman et $\mathrm{al}^{1}$ and Jellis ${ }^{2}$ are based on the clinical staging of HIV disease without reference to CD4 counts. These studies are not blind and infection is not scored objectively. In that of Hoekman et al, ${ }^{1}$ no prophylactic antibiotics were used. In Jellis' study ${ }^{2}$ a rate of infection of $12 \%$ was recorded in the HIV-negative patients.

We considered that a prospective blind study should be undertaken in good surgical conditions, using prophylactic antibiotics and assessment of infection by wound scoring. The CD4 cell count was considered to be a more objective indicator of immune compromise than clinical staging. It is commonly used as the prime marker of the progression of the disease in developed countries. ${ }^{10}$ Clinical staging is very observer-dependent, and may be confounded by comorbidity which is unrelated to HIV disease.

The principal finding of our study was that in the absence of preoperative contamination, a low rate of wound infection was observed in HIV-positive patients $(3.5 \%)$. This was similar to that $(5 \%)$ observed in healthy controls ( $p=0.396$ ). Of the $28 \mathrm{HIV}$-positive patients in this group only one had superficial sepsis and this did not compromise 
the result. Previous studies have not demonstrated this important finding.

Infection was common when there was preoperative contamination $(42 \%)$. This is consistent with the findings of previous studies. ${ }^{2,8}$ Our open fracture group was too small to confirm statistical significance between rates of infection in HIV-positive and HIV-negative patients $(p=0.084)$. An increased risk of infection in HIV-positive patients with open wounds is also consistent with dental studies, which have shown a high rate of infection when operating through the contaminated field of the mouth, but a lower rate for other types of facial implant surgery in HIV-positive patients. ${ }^{11,12}$ A cogent hypothesis is that the risk of infection relates to the bacterial load at the wound site before or during surgery. Immunocompromised patients have a reduced capacity to resist the higher load which occurs in open fractures or contaminated surgery. Prophylactic antibiotics can offset, but cannot eliminate this deficiency.

Our study analysed two main variables within the HIVpositive group which might be expected to affect the incidence of wound infection. These are the degree of preoperative contamination (risk category) and the degree of immunocompromise (CD4 cell count). Of these, the risk category correlated with the incidence of infection $(p=0.036)$. A relationship with the CD4 cell count was not demonstrated $(r=0.13)$.

When uncontaminated patients (risk category 0) are being considered, a very large study would be required to reveal a possible correlation between a low CD4 cell count and an increasing risk of infection since infections are rare in this group regardless of the CD4 cell count. The most important issue is bacterial contamination, not the degree of host immunocompromise.

It has been suggested that late infections may arise around implants as HIV disease progresses. ${ }^{2}$ We did not address this potential problem, but since patients were followed up for three months most of those with fractures had progressed to union. We would hope that further study will identify the risk of late infection. Should this represent a clinical problem, implants should be removed from HIV patients soon after union. Arthroplasty in HIV-positive patients presents a different issue as the implant cannot be removed without comprising the functional outcome.

We believe that implant surgery can be undertaken safely in HIV-positive patients, if the skin is unbroken preoperatively and the surgical conditions are optimal. This applies even in the presence of profound immune compromise. In HIV-positive patients with preoperative contamination, however, the incidence of wound infection increases dramatically.

The authors wish to thank Dr N. Mkandawire, Mr M. Yesaya, and Mr R. Fudzelani for help with this study.

No benefits in any form have been received or will be received from a commercial party related directly or indirectly to the subject of this article.

\section{References}

1. Hoekman P, van de Perre P, Nelissen J, et al. Increased frequency of infection after open reduction of fractures in patients who are seropositive for human immunodeficiency virus. J Bone Joint Surg [Am] 1991;73-A:675-9.

2. Jellis JE. Orthopaedic surgery and HIV disease in Africa. Int Orthop 1996;20:253-6.

3. Tran HS, Moncure M, Tarnoff M, et al. Predictors of operative outcome in patients with human immunodeficiency virus infection and acquired immunodeficiency syndrome. Am $J$ Surg 2000;180:228-33.

4. Savioz D, Chilcott M, Ludwig C, et al. Preoperative counts of CD4 T-lymphocytes and early postoperative infective complications in HIV-positive patients. Eur J Surg 1998;164:483-7.

5. World Health Organisation Acquired Immunodeficiency Syndrome (AIDS). Interim proposal for WHO staging system for HIV infection and disease. Weekly Epidemiol Rec 1990;65:221-8.

6. Wilson AP, Treasure T, Sturridge MF, Gruneburg RN. A scoring method (ASEPSIS) for postoperative wound infections for use in clinical trials of antibiotic prophylaxis. Lancet 1986;1:311-3.

7. Surgical Infection Study Group. Proposed definitions for the audit of postoperative infection: a discussion paper. Ann $R$ Coll Surg Eng 1991;73:385-8.

8. Paiement GD, Hymes RA, LaDouceur MS, Gosselin RA, Green HD. Postoperative infections in asymptomatic HIV-seropositive orthopaedic trauma patients. J Trauma 1994;37:545-50.

9. Cairns J. Surgery in high-HIV incidence poor countries. Trop Doct 2000;30:37-9.

10. Luck JV, Logan LR, Benson DR, Glasser DB. Human immunodeficiency virus infection: complications and outcome of orthopaedic surgery. J Am Acad Orthop Surg 1996;4:297-304.

11. Martinezgimeno C, Acerosanz J, Martinsastre R, Navarrovila C. Maxillofacial trauma: influence of HIV-infection. J Craniomax Surg 1992;20:297-302.

12. Schmidt B, Kearns G, Perrott D, Kaban LB. Infection following treatment of mandibular fractures in human immunodeficiency virus seropositive patients. J Oral Maxillofac Surg 1995;53:1134-9. 